\title{
Implementasi Layanan Cloud Computing Software As a Service Pada Usaha Mikro Kecil dan Menengah
}

\author{
Rifky Lana Rahardian ${ }^{1}$, Linawati ${ }^{2}$, Made Sudarma ${ }^{3}$
}

\begin{abstract}
MSMEs (Micro and Small and Medium Enterprises) have an important role now in the ASEAN economy. 96\% of companies in ASEAN are MSMEs. Although MSMEs have shown their role, they still face various obstacles and constraints such as lack of information, weak branding, promotion and infrastructure. The application of information technology will certainly make it easier for MSMEs to strengthen branding, business processing and enable cooperation with other parties to provide added value to MSMEs.

The application of cloud computing or cloud computing is considered suitable for MSMEs that have limited resources in the form of capital, human resources (HR) and information technology infrastructure. Responding to the importance of the application of information technology to these MSMEs, the research aims to design and build systems that can facilitate MSMEs by utilizing cloud computing technology with SAAS (software as a service).

The system has been tested by testing carried out using the blackbox method which is considered to be running optimally, functionally the system built can produce the output expected by the MSMEe participants. Usability testing to measure the level of satisfaction (user satisfaction) with the usability scale (SUS) system method is also felt necessary so that the system is designed and built according to user needs and satisfaction. With the results of the calculation of SUS 72.25 which means that it belongs to class B or above the average makes SAAS cloud computing services a system that can be accepted by MSMEs participants in supporting their business.
\end{abstract}

\section{Keywords: Cloud Computing, SAAS, Software As A Service, Micro} Small and Medium Enterprises, MSMEs

Intisari- UMKM (Usaha Mikro Kecil dan Menengah) memiliki peranan penting saat ini pada perekonomian ASEAN. 96\% dari perusahaan yang ada di ASEAN merupakan UMKM. Walaupun UMKM telah menunjukkan peranannya namun masih menghadapi berbagai hambatan dan kendala seperti minimnya informasi, lemahnya branding, promosi dan infrastruktur. Penerapan teknologi informasi tentunya akan memberikan kemudahan pada UMKM.

Penerapan cloud computing atau komputasi awan dinilai cocok untuk UMKM yang memiliki keterbatasan sumberdaya berupa modal, sumber daya manusia (SDM) dan infrastruktur teknologi informasi. Menyikapi pentingnya penerapan teknologi informasi pada UMKM ini, maka penelitian bertujuan untuk merancangan dan membangun sistem yang dapat memfasilitasi UMKM dengan memanfaatkan teknologi cloud computing dengan layanan SAAS (software as a service).

${ }^{1}$ Mahasiswa Jurusan Teknik Elektro dan Komputer Fakultas Teknik Universitas Udayana, Jln Tunjung Sari Gg Menuri 4A No 6 Denpasar 80361 INDONESIA (tlp: 0361 8444050; fax: - ; e-mail: hellboy.kiki@gmail.com

${ }^{2,3}$ Dosen Jurusan Teknik Elektro dan Komputer Fakultas Teknik Universitas Udayana, Jln. Jalan Kampus Bukit Jimbaran 80361 INDONESIA (telp: 0361-703315; fax: 0361-4321; e-mail:

22Lina1wati@gmail.com³imasudarma@gmail.com
Sistem telah diuji dengan pengujian yang dilakukan dengan menggunakan metode blackbox dinilai berjalan sudah cukup maksimal, secara fungsional sistem yang dibangun sudah dapat menghasilkan output yang diharapkan oleh peserta UMKM. Pengujian usability untuk mengukur tingkat satisfaction (kepuasan user) dengan metode system usability scale (SUS) juga dirasa perlu sehingga sistem yang dirancang dan dibangun sesuai dengan kebutuhan dan kepuasan user. Dengan hasil perhitungan SUS 72.25 yang berarti termasuk kedalam kelas B atau diatas rata-rata menjadikan layanan cloud computing SAAS ini sistem yang dapat diterima oleh peserta UMKM dalam menunjang bisnis mereka.

Kata Kunci-Cloud Computing, SAAS, Software As A Service, Usaha Mikro Kecil dan Menengah, UMKM

\section{PENDAHULUAN}

Salah satu pilar utama ekonomi nasional yang harus memperoleh prioritas, perlindungan, dukungan dan pengembangan seluas-luasnya adalah UMKM, selain menjadi bagian penting bagi roda perekonomian tanah air, UMKM juga memegang peranan penting bagi perekonomian ASEAN karena hingga saat ini $96 \%$ dari perusahaan ASEAN merupakan UMKM [1].

Undang-undang Nomor 20 tahun 2008 menyebutkan walaupun telah menunjukkan peranannya dalam perekonomian nasional, namun UMKM masih menghadapi berbagai hambatan dan kendala, seperti pengolahan proses bisnis, kegiatan pemasaran atau promosi yang masih konvensional, SDM, teknologi dan desain. Hal ini terjadi karena minimnya informasi yang didapat oleh peserta UMKM dan kurangnya sentuhan teknologi. Kendala lain yang sering dihadapi adalah UMKM tidak sanggup dan tidak mau mengeluarkan biaya lebih untuk menerapkan teknologi informasi seperti pembuatan data center, membeli perangkat server atau membangun infrastruktur jaringan lain yang memerlukan biaya investasi yang sangat mahal dan sulit dalam pengoperasian. Banyaknya UMKM yang belum menerapkan sentuhan teknologi informasi pada proses bisnisnya, membuat penulis ingin membangun sistem yang dapat diterima oleh UMKM [2]. Dari hasil pengumpulan data baik secara primer dan sekunder, penulis belum menemukan penelitian sejenis yang sudah digunakan atau diterapkan oleh UMKM.

Teknologi komputasi awan merupakan salah satu solusi yang diharapkan dapat mengoptimalkan pengelolaan UMKM. Penerapan komputasi awan memiliki efisiensi dan efektifitas yang tinggi karena seluruh proses komputasi, perangkat lunak hingga infrastruktur dilakukan secara virtual tanpa harus menginvestasikan modal besar untuk pengadaannya. Teknologi ini dinilai cocok pada usaha yang memiliki keterbatasan sumberdaya khususnya sumber daya manusia dan infrastruktur teknologi informasi seperti UMKM [3]. Seluruh informasi yang berkaitan dengan para pelanggan

Rifky Lana Rahardian dkk: Implementasi Layanan Cloud Computing ...

p-ISSN:1693 - 2951; e-ISSN: 2503-2372 
sebagai penyedia jasa dan penjual produk akan disimpan dalam sebuah database sehingga perusahaan mengenali pelanggan dan sebaliknya untuk memberikan pelayanan yang tepat bagi pelanggannya [4].

Pentingnya penerapan teknologi informasi pada UMKM, maka penulis akan merancang dan membangun sistem berbasis cloud computing dengan layanan SAAS yang dapat digunakan oleh UMKM dalam proses bisnis dan promosi yang diharapkan. Sistem yang akan dibangun juga akan diuji tingkat kemudahan pengguna agar dapat diterima dengan baik oleh user. Sehingga hasil penelitian ini kedepannya dapat dijadikan sebagai wadah bagi UMKM dalam memulai usahanya. Berbeda dengan penelitian yang sudah ada seperti rancang bangun suatu sistem informasi yang memerlukan biaya besar seperti membeli server dan perangkat jaringan yang mahal ketika memulai bisnisnya, penelitian ini dikhususkan pada pengusaha yang ingin memulai usahanya dengan budget atau modal yang kecil.

\section{CLOUD COMPUTING}

\section{A. Cloud Computing}

Cloud computing adalah sistem komputasi yang parallel dan tersebar dimana terdiri dari beberapa kumpulan komputer yang terhubung secara virtual yang ditampilkan sebagai satu atau lebih sumber daya yang dapat digunakan oleh konsumen melalui persetujuan diantara pelanggan dan penyedia jasa [5].

Secara umum penerapan konsep cloud computing untuk kegiatan sehari-hari adalah penggunaan aplikasi pekerjaan secara online. Dimana para pengguna tidak memerlukan untuk membeli perangkat lunak untuk melakukan pekerjaan, karena sudah tersedia di internet. Penyedia jasa dalam hal ini menyediakan akses jaringan, keamanan, perangkat lunak aplikasi dan tempat penyimpanan data dalam bentuk pusat data yang terletak di internet [6].

Cloud computing memiliki beberapa mode yang ditawarkan yaitu:

a. Infrastruktur As A Service (IAAS) yaitu penyedia jasa cloud computing yang menyediakan kemampuan penyimpanan data, pemrosesan data, jaringan dan sumber daya komputasi lainnya kepada pelanggan dan mengizinkan pelanggan untuk menjalankan perangkat lunak yang mengendalikan sumber daya komputasi tersebut.

b. Platform As A Service (PAAS) yaitu penyedia jasa cloud computing yang menyediakan tempat untuk menjalankan aplikasi yang dikembangkan oleh pelanggan menggunakan alat-alat yang disediakan oleh penyedia jasa. Konsumen hanya bisa mengendalikan ruang lingkup aplikasi yang berjalan.

c. Software As A Service (SAAS) penyedia jasa cloud computing yang menyediakan aplikasi yang berada di infrastruktur cloud dan siap digunakan oleh konsumen. Penggunaan aplikasi bisa diakses melalui berbagai peralatan yang terhubung dengan jaringan internet [6].

B. Usaha Mikro, Kecil dan Menengah (UMKM)

Kriteria UMKM tercantum dalam UU UMKM Republik Indonesia Nomor 20 tahun 2008. Kriteria untuk ketiga jenis usaha tersebut dapat dilihat pada Tabel 1 :
TABEL I

KRITERIA UMKM

\begin{tabular}{|c|c|c|}
\hline Usaha & Asset & Omzet \\
\hline Usaha Mikro & Maks 50 Juta & Maks 300 Juta \\
\hline Usaha Kecil & $>50-500$ Juta & $\begin{array}{c}>300 \text { Juta-2,5 } \\
\text { Miliar }\end{array}$ \\
\hline Usaha Menengah & $\begin{array}{c}>500 \text { Juta }-10 \\
\text { Miliar }\end{array}$ & $>2,5-50$ Miliar \\
\hline
\end{tabular}

UMKM memiliki peran yang penting dalam perekonomian Indonesia. Data dari Departemen Koperasi dan UKM menunjukkan jumlah UMKM pada tahun 2008 meningkat dibandingkan tahun 2007. Pada tahun 2007 jumlah UMKM sebanyak 49,82 juta unit, sedangkan pada 2008 meningkat mencapai 51,26 juta unit. Produk Domestik Bruto UKM pada tahun 2008 mencapai Rp. 2.609 triliun, dimana sebesar Rp. 1.505 triliun diantaranya disumbangkan oleh unit-unit usaha mikro. UMKM mampu menyerap rata-rata dari $90 \%$ tenaga kerja dari total tenaga kerja yang ada. Saat ini jumlah UMKM di kota Denpasar sudah mencapai sekitar 31.826 unit dengan klasifikasi UMKM mikro, kecil maupun menengah. Untuk jenis usaha terdiri dari perdagangan, aneka usaha, industri pertanian dan industri non pertanian [7].

\section{Komponen Satisfaction}

Komponen yang digunakan dalam mengukur tingkat kepuasan user terhadap sistem salah satunya adalah melalui kuesioner System Usability Scale (SUS) yang memiliki sepuluh pertanyaan tentang sistem yang dibangun. System Usability Scale merupakan pengujian usability yang handal dan efektif untuk digunakan pada berbagai aplikasi. Dalam kuesioner ini menggunakan penilaian skala likert, dimana masing-masing dibuat dengan menggunakan skala 1- 5 kategori jawaban, dengan rincian sebagai berikut:

\section{SS berarti "sangat setuju" \\ 2. S berartiya "setuju" \\ 3. N berarti "netral" \\ 4. TS berarti "tidak setuju" \\ 5. STS berarti "sangat tidak setuju"}

Skor akhir SUS mempunyai rentang nilai 0-100, sedangkan nilai setiap pernyataan mempunyai rentang nilai $0-4$. Skor diolah dengan menghitung nilai pada pernyataan, kemudian skor dari setiap pernyataan dijumlahkan dan mengalihkan hasil jumlahan dengan 2.5 untuk mendapatkan nilai tertinggi 100.

Berdasarkan skor akhir SUS tersebut akan diketahui apakah sistem yang dibangun memiliki kemudahan akses dan apakah sistem yang dibangun dapat diterima dengan baik oleh user $[8]$.

\section{MYSQL}

MySQL adalah user database yang menggunakan bahasa Structured Query Language (SQL). MySQL dalam operasi client-server melibatkan server dan berbagai program serta library yang berjalan disisi client. Bahasa ini pada awalnya dikembangkan oleh IBM. Namun tekah diadopsi dan digunakan sebagai standar industry. Dengan menggunakan bahasa SQL, proses akses database menjadi lebih userfriendly [9]. 


\section{ALUR PENELITIAN}

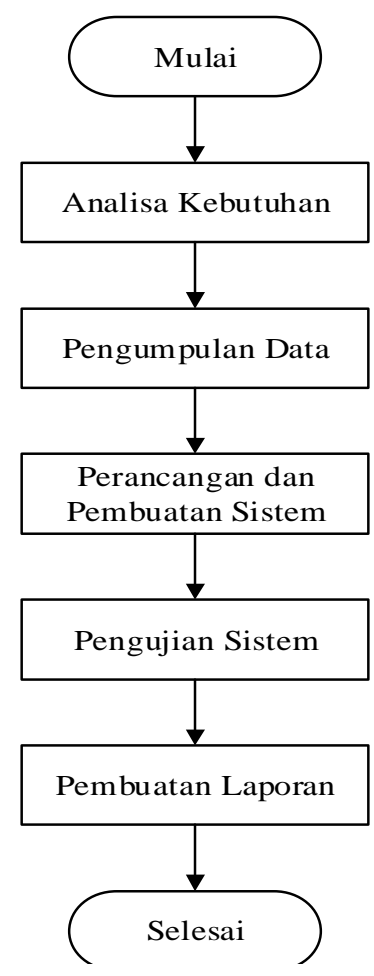

Gambar 1: Alur Penelitian

\section{A. Analisa Kebutuhan}

Pada tahap ini dilakukan analisa dengan wawancara dan observasi langsung kepada peserta UMKM terhadap kebutuhan yang mendukung penelitian ini mengenai layanan software as a service, dimana kebutuhan-kebutuhan tersebut akan digunakan dari tahap awal hingga penyelesaian penelitian. Kebutuhan-kebutuhan tersebut meliputi aplikasi apa saja yang diperlukan, layanan seperti apa yang akan dibangun, teknik pembayaran untuk pengguna layanan dan data-data kebutuhan transaksi bisnis UMKM secara umum.

B. Pengumpulan Data

Berdasarkan kebutuhan, maka data yang akan dikumpulkan untuk mendukung penelitian ini adalah penelitian-penelitian yang telah ada sebelumnya yang terkait dengan penelitian ini yaitu penelitian tentang cloud computing, software as a service (SAAS), dan UMKM. Data-data yang dikumpulkan difokuskan kepada data-data kebutuhan bisnis UMKM secara umum serta metode pembayaran yang cocok digunakan dalam penggunaan teknologi ini.

C. Perancangan dan Pembuatan Sistem

Pada tahap ini akan dilakukan perancangan sistem dengan menggunakan diagram-diagram Unified Modelling Language (UML), dan diagram yang dimaksud tersebut adalah Use Case Diagram, Acitivity Diagram, Sequence Diagram, dan Class Diagram. Untuk merancang database akan digunakan Entity Relationship Diagram (ERD).

Setelah perancangan sistem, akan dilakukan pembuatan sistem. Aplikasi yang akan digunakan adalah JetBrains PhpStrom IDE dengan bahasa pemrograman PHP dan
XAMPP dengan MySQL sebagai aplikasi untuk membangin database.

D. Pengujian Sistem

Pada tahap ini akan dilakukan pengujiian terhadap sistem yang telah berhasil dibuat. Pengujian yang akan dilakukan adalah pengujian fungsionalitas sistem apakah sudah berjalan sesuai dengan apa yang diharapkan oleh user. Pengujian sistem yang digunakan adalah pengujian blackbox.

Setelah melakukan pengujian sistem, selanjutnya akan melakukan pengujian user untuk mengukur tingkat kepuasan user dengan kuesioner SUS yang disebar secara acak kepada 10 responden peserta UMKM.

\section{IV.HASIL DAN PEMBAHASAN}

A. Hasil perancangan dan implementasi sistem

Hasil perancangan sistem menggunakan diagram UML menjelaskan bahwa terdapat 5 aktor yang saling terhubung atau saling berinteraksi satu sama lain. Dijelaskan bahwa admin cloud sebagai penyedia layanan memiliki akses untuk login, mengolah data admin, mengolah data paket,dan mengolah data pembayan. Admin UMKM memiliki akses untuk login, mengolah data kategori, mengolah data produk, mengolah data penjualan, melihat data customer, dan mengolah data UMKM. Pengunjung provider hanya dapat melihat data paket dan melakukan registrasi UMKM jika ingin berlangganan. Pengunjung UMKM hanya dapat melihat daftar produk dan melakukan registrasi customer. Dan terakhir customer adalah user yang dapat melakukan login sebagai customer dan melakukan pemesanan kepada piham UMKM.

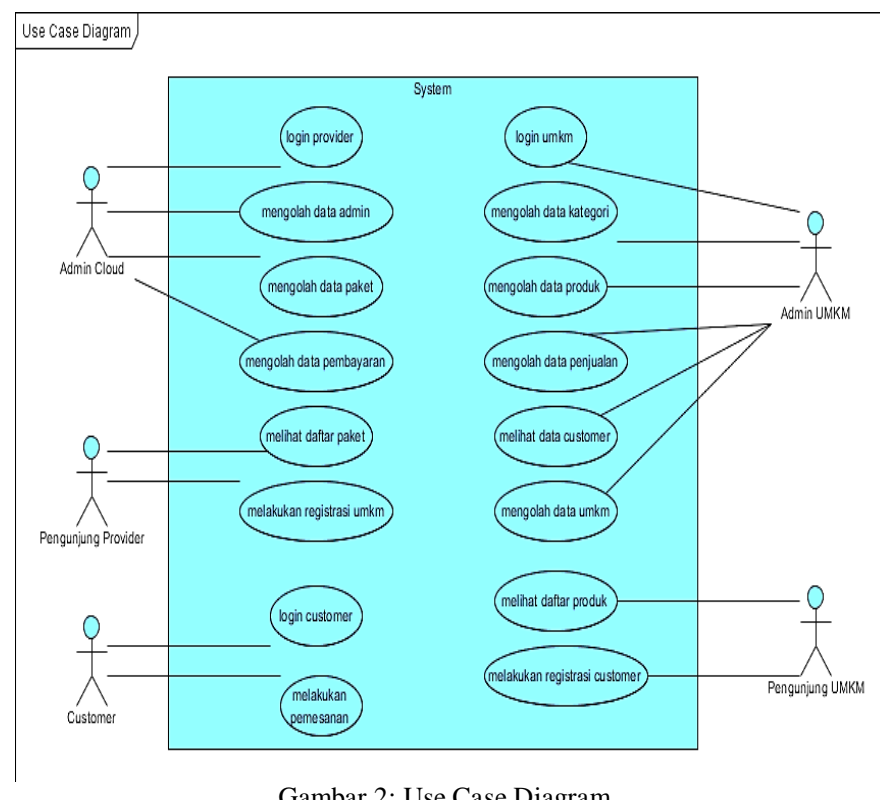

Setelah melakukan perancangan dan pembuatan aplikasi, selanjutnya aplikasi yang dibuat di hosting pada penyedia hosting cloud Digital Ocean dengan nama domain umkmgroup.com. Dengan spesifikasi SO Ubuntu Linux 16.04.4. Processor Intel(R) Xeon(R) CPU E5-2650 v4 @ 2.20 GHz, 1 cores. RAM 1GB dan SSD 25GB. 


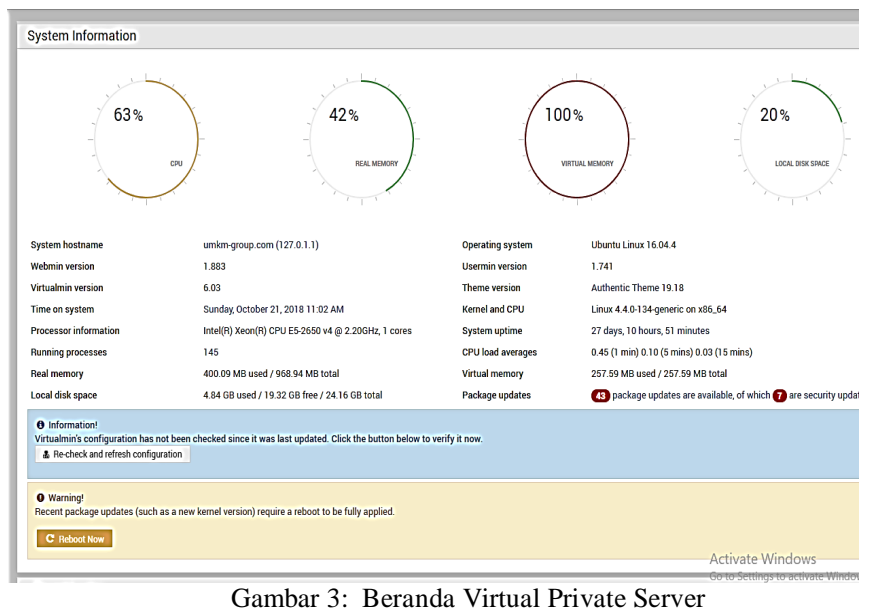

Halaman beranda adalah halaman yang akan pertama kali muncul ketika mengakses website http://umkm-group.com.

Berdasarkan grafik yang penulis pantau tiap harinya, penggunaan Disk usage atau penyimpanan pada server cloud belum menyentuh $33 \%$ dari total 25GB SSD yang ada sehingga penyedia layanan masih dapat menampung UMKM yang ingin mendaftar. Penggunaan CPU, Memory dan Disk I/O rata-rata trafik tinggi pada pukul 10:00 - 11:00 AM di tiap harinya. Kesimpulan yang didapat adalah padatnya transaksi yang terjadi pada aplikasi SAAS ini terjadi pada pukul 10:00 sampai 11:00 AM tiap harinya.

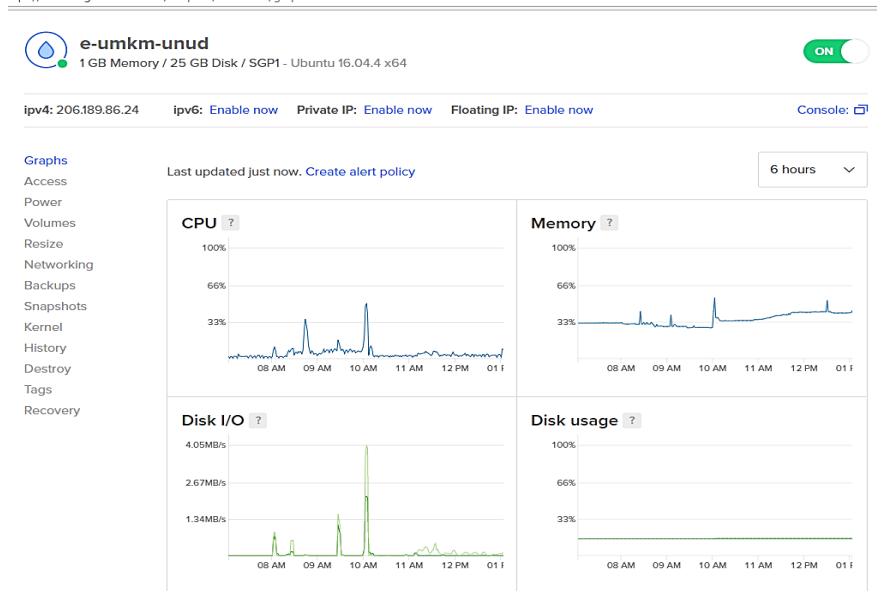

Gambar 4: Grafik penggunaan server cloud

B. Hasil Pengujian Blackbox

Pengujian dilakukan dengan menguji setiap proses mulai dari proses login sampai proses bisnis terjadi untuk mencari kemungkinan terdapat halaman yang masih belum berjalan sesuai fungsinya atau error. Pengujian dilakukan pada proses Login admin cloud, pendaftaran cloud, konfirmasi pembayaran cloud, login aplikasi e-commerce, pendaftaran member, order, penambahan data produk, penambahan kategori, penambahan data provinsi, penambahan kota, dan pengubahan profil.

Berdasarkan pengujian blackbox yang terlah dilakukan maka hasil yang didapat adalah proses yang berjalan pada sistem mulai dari proses login sampai proses bisnis berjalan adalah sudah benar. Secara fungsi dan fitur yang terdapat pada

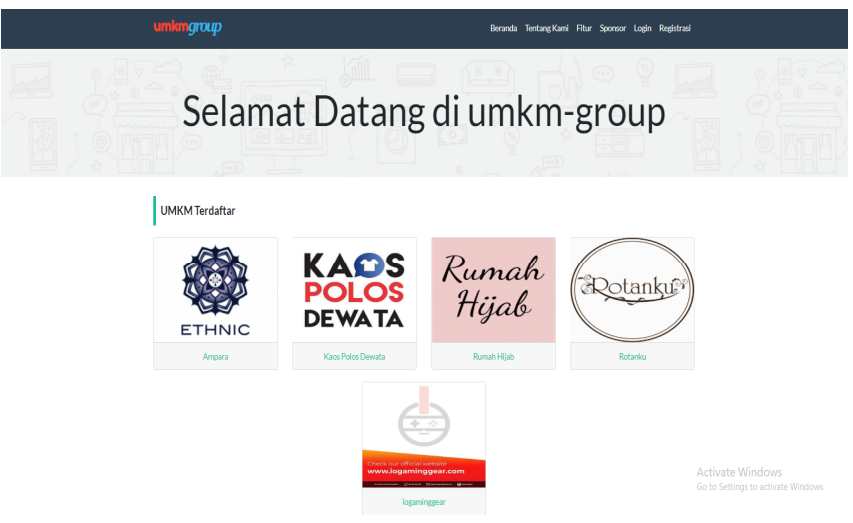

Gambar 5: Halaman Beranda

sistem sudah dapat menghasilkan output atau keluaran yang diharapkan oleh user.

\section{Pengujian Usability}

Pengujian usability untuk mengukur tingkat kepuasan user adalah data kuesioner SUS yang disebarkan kepada 10 responden peserta UMKM.

TABEL II

PERTANYAAN KUESIONER

\begin{tabular}{|l|l|}
\hline No & \multicolumn{1}{c|}{ Pertanyaan } \\
\hline 1 & Saya akan sering menggunakan aplikasi ini \\
\hline 2 & Terdapat beberapa fitur aplikasi yang sulit digunakan \\
\hline 3 & Aplikasi ini mudah digunakan \\
\hline 4 & $\begin{array}{l}\text { Saya membutuhkan bantuan seorang teknisi agar bisa } \\
\text { lancar menggunakan aplikasi ini }\end{array}$ \\
\hline 5 & $\begin{array}{l}\text { Fitur-fitur aplikasi ini sudah terintegrasi dengan baik satu } \\
\text { sama lain }\end{array}$ \\
\hline 6 & Terlalu banyak ketidak konsistenan dalam aplikasi ini \\
\hline 7 & $\begin{array}{l}\text { Orang-orang akan sangat cepat bisa menggunakan } \\
\text { aplikasi ini }\end{array}$ \\
\hline 8 & $\begin{array}{l}\text { Hasil yang ditampilkan aplikasi sesuai dengan kebutuhan } \\
\text { atau keinginan anda }\end{array}$ \\
\hline 9 & $\begin{array}{l}\text { Dibutuhkan pelatihan sebelum mulai menggunakan } \\
\text { aplikasi ini }\end{array}$ \\
\hline 10 & Saya merasa puas menggunakan aplikasi ini \\
\hline
\end{tabular}

TABEL III

Hasil Tabulasi Skor Tiap Pertanyaan

\begin{tabular}{|c|c|c|c|c|c|c|c|c|c|c|c|}
\hline \multirow{2}{*}{$\begin{array}{c}\text { Responden } \\
\text { ke- }\end{array}$} & \multirow{2}{*}{ Nama } & \multicolumn{10}{|c|}{ Pertanyaan } \\
\hline & & 1 & 2 & 3 & 4 & 5 & 6 & 7 & 8 & 9 & 10 \\
\hline 1 & $\begin{array}{l}\text { Rumah Hijab } \\
\text { (Busana Muslim } \\
\text { Keluarga) }\end{array}$ & 3 & 3 & 3 & 4 & 2 & 4 & 4 & 4 & 2 & 3 \\
\hline 2 & Arakyu Shop & 4 & 2 & 3 & 3 & 2 & 4 & 3 & 4 & 3 & 4 \\
\hline 3 & Ampara & 4 & 4 & 3 & 4 & 3 & 4 & 2 & 4 & 3 & 3 \\
\hline 4 & Mrs. Crepe & 3 & 2 & 4 & 0 & 3 & 2 & 3 & 3 & 1 & 3 \\
\hline 5 & Pie Susu Putri & 3 & 2 & 3 & 1 & 3 & 3 & 3 & 3 & 0 & 4 \\
\hline 6 & $\begin{array}{l}\text { BagoesBAli } \\
\text { (Produksi Busana } \\
\text { Muslim Anak) }\end{array}$ & 4 & 3 & 3 & 3 & 4 & 3 & 2 & 3 & 0 & 3 \\
\hline 7 & $\begin{array}{l}\text { AY Florist } \\
\text { (Kerajinan } \\
\text { Tangan Bunga } \\
\text { Flanel) }\end{array}$ & 3 & 3 & 3 & 4 & 3 & 3 & 3 & 3 & 1 & 3 \\
\hline 8 & IO Gaming Gear & 4 & 4 & 3 & 3 & 4 & 3 & 3 & 3 & 0 & 4 \\
\hline 9 & Gotcha IT & 3 & 3 & 3 & 2 & 3 & 2 & 2 & 3 & 1 & 3 \\
\hline 10 & Lets Vape & 3 & 3 & 3 & 3 & 3 & 3 & 2 & 3 & 2 & 4 \\
\hline
\end{tabular}


Majalah Ilmiah Teknologi Elektro, Vol. 17, No. 3, September - Desember 2018

DOI: https://doi.org/10.24843/MITE.2018.v17i03.P10

Jika dikonversi untuk mendapatkan hasil skor dari kuesioner SUS sesuai dengan persamaan, maka akan mendapatkan data seperti Tabel 4 :

TABEL IV

HASIL KONVERSI KUESIONER SUS

\begin{tabular}{|c|c|c|c|c|c|c|c|c|c|c|c|c|}
\hline \multirow{2}{*}{$\begin{array}{c}\text { Responden } \\
\text { ke- }\end{array}$} & $\mathbf{1}$ & $\mathbf{2}$ & $\mathbf{3}$ & $\mathbf{4}$ & $\mathbf{5}$ & $\mathbf{6}$ & $\mathbf{7}$ & $\mathbf{8}$ & $\mathbf{9}$ & $\mathbf{1 0}$ & Total & $\begin{array}{c}\text { Score } \\
\text { SUS }\end{array}$ \\
\hline $\mathbf{1}$ & 3 & 3 & 3 & 4 & 2 & 4 & 4 & 4 & 2 & 3 & 32 & 80 \\
\hline $\mathbf{2}$ & 4 & 2 & 3 & 3 & 2 & 4 & 3 & 4 & 3 & 4 & 32 & 80 \\
\hline $\mathbf{3}$ & 4 & 4 & 3 & 4 & 3 & 4 & 2 & 4 & 3 & 3 & 34 & 85 \\
\hline $\mathbf{4}$ & 3 & 2 & 4 & 0 & 3 & 2 & 3 & 3 & 1 & 3 & 24 & 60 \\
\hline $\mathbf{5}$ & 3 & 2 & 3 & 1 & 3 & 3 & 3 & 3 & 0 & 4 & 25 & 62.5 \\
\hline $\mathbf{6}$ & 4 & 3 & 3 & 3 & 4 & 3 & 2 & 3 & 0 & 3 & 28 & 70 \\
\hline $\mathbf{7}$ & 3 & 3 & 3 & 4 & 3 & 3 & 3 & 3 & 1 & 3 & 29 & 72.5 \\
\hline $\mathbf{8}$ & 4 & 4 & 3 & 3 & 4 & 3 & 3 & 3 & 0 & 4 & 31 & 77.5 \\
\hline $\mathbf{9}$ & 3 & 3 & 3 & 2 & 3 & 2 & 2 & 3 & 1 & 3 & 25 & 62.5 \\
\hline $\mathbf{1 0}$ & 3 & 3 & 3 & 3 & 3 & 3 & 2 & 3 & 2 & 4 & 29 & 72.5 \\
\hline \multicolumn{10}{|c|}{ Rata-rata } \\
\hline \multicolumn{10}{|c|}{} \\
\hline
\end{tabular}

Hasil pengukuran tingkat kepuasan user sebesar 72.25 yang berarti user puas terhadap sistem dan sistem memiliki kualitas yang baik jika dilihat dari grafik ranking SUS Score [10].

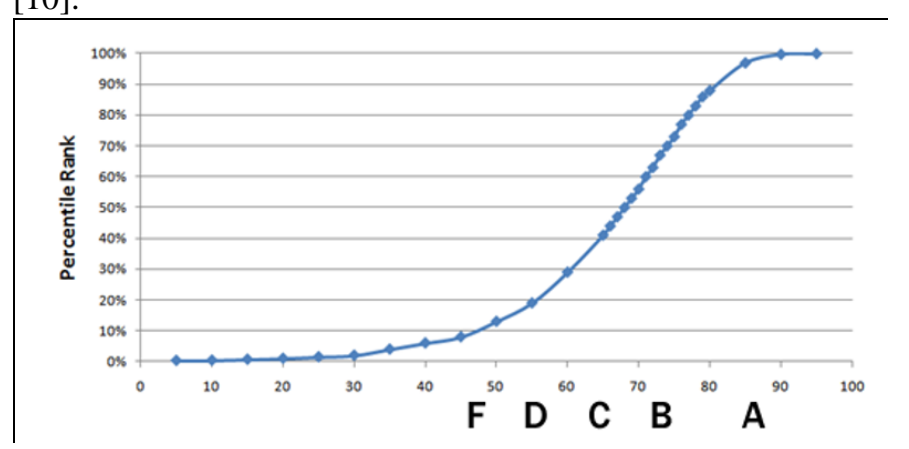

Gambar 6: Grafik Ranking SUS Score

Berdasarkan hasil pengujian pada sistem ini kepuasan yang dirasakan pengguna sistem pendapatkan skor 72.25 hal ini menunjukkan bahwa tingkat kepuasan dari pengguna memiliki nilai B dimana sistem sudah diatas rata-rata.

D. E-UMKM sebagai layanan SAAS berbiaya rendah

Dengan berlangganan hosting cloud dan Virtual Private Server pada Digital Ocean sejumlah 5 dollar per bulan atau kurang lebih Rp. 72.415, sehingga per tahun modal yang dibutuhkan adalah sebesar Rp. 868.980 maka harga yang cocok untuk UMKM dan perbandingan biaya dengan layanan lain yang sudah ada dapat dilihat pada Tabel 5 :

TABEL V

PERBANDINGAN BIAYA LAYANAN

\begin{tabular}{|c|c|c|c|c|}
\hline No & Perbandingan & & E-UMKM & Penyedia Lain \\
\hline 1 & Harga & & $\begin{array}{l}\text { Free (gratis } \\
\text { selamanya }\end{array}$ & 1. $\begin{array}{l}\text { Jarvis Store } \\
\text { (bulanan) }\end{array}$ \\
\hline
\end{tabular}

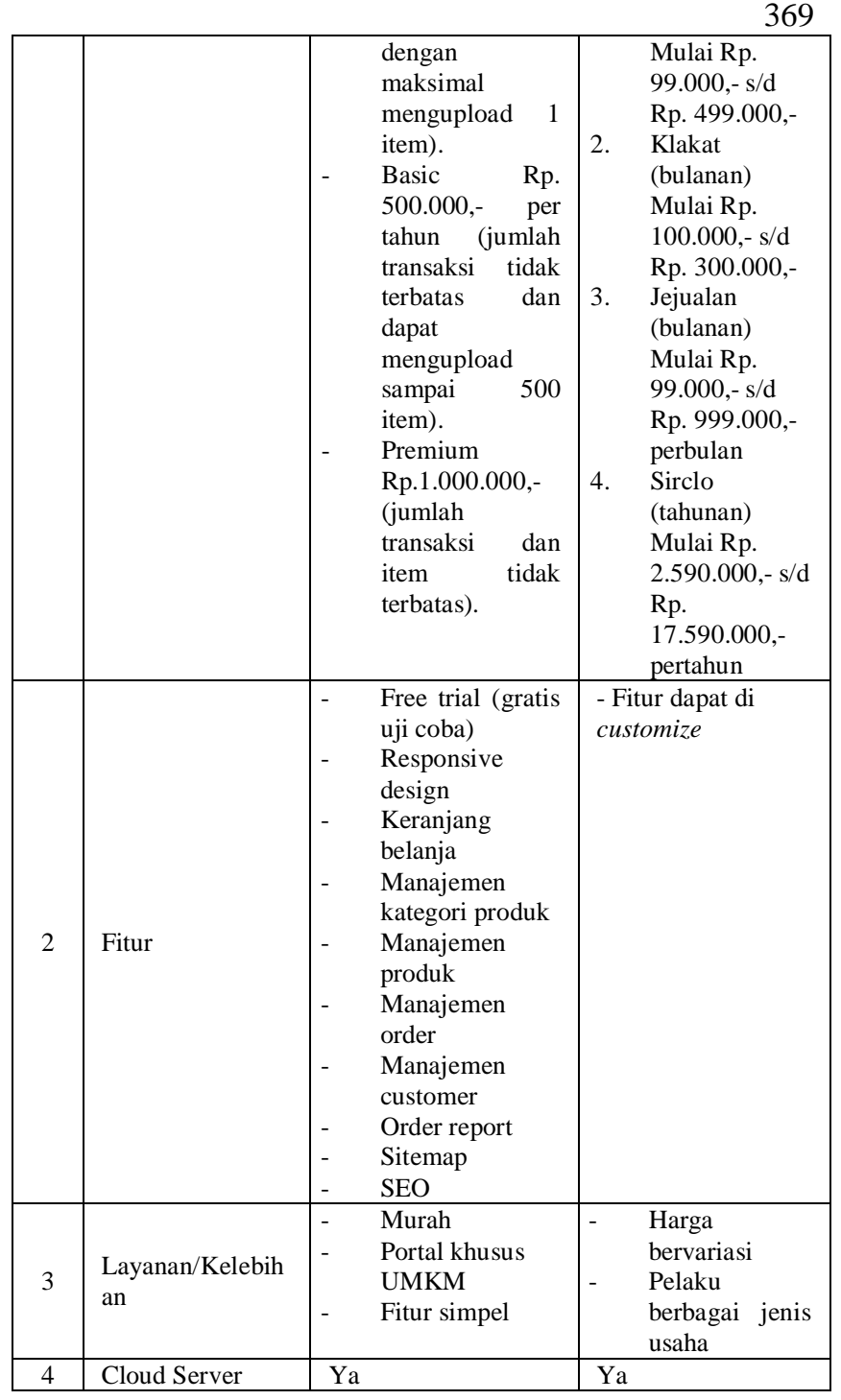

\section{KESIMPULAN}

Implementasi cloud computing software as a service pada UMKM dapat berjalan sesuai dengan tujuannya sehingga pengguna tidak perlu melakukan investasi yang besar dan hanya membayar sesuai dengan kebutuhan. Aplikasi $e$ commerce dalam bentuk software as a service telah berhasil dirancang dan dibangun dengan fitur-fitur siap pakai sehingga dapat mempermudah pengguna dalam membangun aplikasi e-commerce atau aplikasi penjualan pada UMKM.

Hasil pengujian blackbox memberikan kesimpulan bahwa proses yang berjalan mulai dari proses login sampai terjadinya proses bisnis sudah sesuai dengan rancangan yang dibuat. Seluruh form dan fitur berjalan sesuai dengan fungsinya. Secara umum sistem yang dibangun sudah dapat menghasilkan output atau keluaran yang diharapkan oleh user.

Berdasarkan hasil pengujian pada sistem ini dengan menggunakan usability pengukuran tingkat satisfaction yang didapatkan dari sistem ini diantaranya kepuasan yang dirasakan pengguna sistem mendapatkan skor 72.25 sesuai

Rifky Lana Rahardian dkk: Implementasi Layanan Cloud Computing ...

p-ISSN:1693 - 2951; e-ISSN: 2503-2372 
dengan hasil yang didapatkan dari analisis. Hasil ini menunjukkan bahwa tingkat kepuasan dari pengguna sistem memiliki nilai B dimana sistem berada diatas standar dan dapat diterima dengan baik.

\section{REFERENSI}

[1] Diangga, 2016, "Majalah Masyarakat ASEAN edisi 12".

[2] Irfan, A., \& Insap Santosa, P, 2015, “Adopsi Cloud Computing Pada UKM Di Indonesia".

[3] Widuri, N., \& Fajardhani, 2011, "Manajemen Resiko Penerapan Komputasi Awan Pada UMKM".

[4] Wissmani, 2010, "Kajian Potensi Implementasi Customer Relationship Management Di Lingkungan Politeknik Negeri Bali”. Jurnal Teknologi Elektro, Vol. 9 No. 1 Januari-Juni 2010.

[5] Wu, L., Garg, S.K., \& Buyya, R, 2011, "SLA-Based Resource Allocation for Software As A Service Provider (SaaS) in Cloud Computing Environments" (IEEE.https://doi.org/10.1109/CCGrid.2011.15).

[6] Katzan, 2010, "On the privacy of cloud computing". (International Journal of Management and Information Systems, Vol.14, No 2 , pp 1-12).

[7] Wirastika, Heny K, Lukman M, 2016, "The Effect of Entrepreneurial Characteristic towards The Business Performance of Palm Sugar Micro, Small and Medium Entreprises in West Lombok Regency”. (Jurnal Penyuluhan, Maret 2016 Vol.12 No.1).

[8] Bangor, A.,Kortum, P.,Miller, J., 2009, "Determining what individual SUS Scores mean: Adding an adjective rating scale". (Journal of usability studies 4, 114-123.doi:66.39.39.113).

[9] Widyantara, Wedanti, Swamardika, 2015, "Desain dan Implementasi Aplikasi Video Surveillance System Berbasis WebSIG”. Jurnal Teknologi Elektro, Vol. 14, No. 1, Januari-Juni 2015.

[10] Sauro, J., Lewis,J.R., 2011, “When designing usability questionnaires, does it hurt to be positive?" (Proceedings of the 2011 Annual Conference on Human Factors in Computing Systems - CHI'11.ACM Press, New York, New York, USA, p. 2215. Doi: 10.1145/1978942.1979266). 